\title{
Evaluation of Utilizing the Magnetic Techniques to Treat the Sulfuric Water Resources in Nineveh Governrate / Iraq
}

\author{
Ayham Taha Al-Rawi* \\ Northern Technical University / Technical Institute in Mosul
}

Received: 12/05/2020

Accepted: 05/08/2020

Published: 20/09/2020

\begin{abstract}
The sulfuric water in Iraq is considered one of the polluted water resources due to their high sulfur contents which reach about (1000 ppm) in Iraqi sulfur springs which consider more than the permitted rate in the global scale limiting (200-400 ppm). So, this study was conducted to treat the water of the sulfur springs by using magnetic techniques, through the identification of the physical and chemical traits before and after treatment as well as determining the validity of these types of water for different uses. The Mosul city contains several sulfur water springs which located in (A) Mosul dam area, (B) area of Ein Kebriet in the center of Mosul, and (C) area of the Hammam-Alalil, where the sulfur water causes contamination of the surface water due to flowing towards the Tigris River. So, magnetic techniques were applied; where the sulfur water was passed for a period of (15 and 30 minutes), through a closed mgnetic circuit of a device which generates a magnetic field of (1000 Gauss). We found, that after the treatment by the magnetic techniques the physical characteristics changed when the yellow sulfur color disappeared and converted to the transparent color. Also, the sulfuric odor disappeared while the chemical properties such as the $\mathrm{pH}$ values found its change; in the site (A) from 6 to 7.1 , in the site (B) from 6.5 to 7.4 and in the site (C) from 9 to 8.4. Moreover, electric conductivity (EC) decreased; in site (A) from $1721 \mathrm{ppm}$ to $17 \mathrm{ppm}$, in the site (B) from $1414 \mathrm{ppm}$ to $15 \mathrm{ppm}$ and in the site (C) from $871 \mathrm{ppm}$ to (9) while the total dissolved solids (TDS) values increased in the site (A) from $3.5 \times 10^{3} \mathrm{ppm}$ to $3.8 \times 10^{3} \mathrm{ppm}$, in the site (B) from $2.8 \times 10^{3} \mathrm{ppm}$ to $3.1 \times 10^{3} \mathrm{ppm}$ and in the site (C) from $1.7 \times 10^{3} \mathrm{ppm}$ to $1.8 \times 10^{3} \mathrm{ppm}$. Due to the efficiency of treatment by increasing the solubility of water contents, and decreased the sulfate values $\left(\mathrm{SO}_{4}\right)$ in site (A) from $1392 \mathrm{ppm}$ to 144, in site (B) from $945 \mathrm{ppm}$ to $95 \mathrm{ppm}$ and in site (C) from 247 to 26, due to their conversion to hydrogen sulfide gas and their volatilization in the atmosphere, which is caused by a fault odor in the laboratory. Thus, the flowing of the treated water to the river contributes in the enrichment of surface water, also possible for its investment in agricultural irrigation.
\end{abstract}

Keywords: Magnetic techniques, Sulfuric water, Nineveh governorate, Iraq

\section{Introduction}

The water resources are an environmental components of the biosphere, interacting with life and economic - social development, where achieving water security means achieving food security. Iraq is located in the semi-arid regions; water resources in Iraq have faced many threats and a lot of damages, especially from neighboring countries such as; Iran, Turkey and Syria, by establishing dams on the sources of rivers. Besides the drought of the marshes in south of Iraq which constitutes half of the water bodies. The issue of water scarcity and pollution in Iraq is one of the most important environmental issues because of its close association with human, agriculture and biodiversity. The problem of water scarcity and poor quality has emerged as a result of population growth, climate change, increasing of human activity, non-rationalization of water consumption and technological progress which caused pollution \& depletion of water resources. That leads us to say that, the desalinated water and treated water are growing water resources with the time and with the meet of increasing population growth and human progress, unlike traditional water resources that are often limited and prone to depletion and pollution. The increase in demand for water, especially in arid and semi-arid areas such as Iraq, poses a major threat to all aspects of development where water resources suffer from many changes in physical and chemical properties which caused by water pollution. Since the majority of industrial constructions and hospitals are built on the banks of rivers. So, the flow of industrial, health and agricultural wastewater to river basins and the absence of partial or total treatment units as well as the loss of optimal and efficient use of water in agriculture (the most water-consuming sector of up to $80 \%$ ), which requires techniques of rationalization of water consumption using sprinkler and drip irrigation systems. The treatments of sulfur water, as well as the recycling of domestic and industrial wastewater and its use in agriculture, reducing the burden on the freshwater resources. Sulfur water contains solids, soluble gases and suspended materials, where the quality of these components depend on biological and environmental factors, which are subject to changes resulting from the interaction of water with its environment directly. The classification and evaluation of sulfuric water depend on concentrations of the chemical components on which this water is classified, such as sulfuric content, salinity, $\mathrm{pH}$ and alkalinity. And the treatment of sulfur water has become an

Corresponding author: Ayham Taha Al-Rawi, Northern Technical University / Technical Institute in Mosul. E-mail: atalrawi@ntu.edu.iq 
important need to raise the productivity and development of water resources in Iraq $[1,2]$. This water contains a high amount of sulfurs $\left(\mathrm{SO}_{4}\right)$, which is emitted into the air as hydrogen sulfide gas $\left(\mathrm{H}_{2} \mathrm{~S}\right)$, which emitted foul-smelling like rotten eggs [3]. The most important areas where sulfuric water is present in several of Nineveh governorate in Iraq as in Mosul dam project in North of Nineveh governorate, Ain Kebriet area in the old Mosul in the center of Nineveh governorate and Hammam Alalil area in South of Nineveh governorate. Water comes out very boiling and from different places where it cures many diseases such as psoriasis, rheumatism and arthritis, and helps to heal wounds that affect the skin [4]. Necessary to benefit from sulfur water with high sulfur content and to invest its water fully for irrigation use to be addressed and reduce the concentration of mineral salts, especially sulfur content within the suitable level for the irrigation. Magnetic technology is a simple attempt to imitate what happens in nature precisely because water when passes through the natural magnetic field become more active so that the process of magnetization reorganizes water charges and the form of these charges is random in normal and contaminated water. The magnetic treatment of water doesn't actually magnetize water and this is considered a commonly wrong idea. Water is not magnetized; it is subjected to a strong magnetic field. However, as with all liquids, it possesses the properties of electromagnetic materials, when exposed to a magnetic field, water will produce a weak magnetic field in the opposite direction, therefore; modified water, air-conditioned water or magnetically treated water is the correct expression to avoid common mistakes [5]. Currently appearance the application of magnetic techniques is used in various fields of life such as medicine, agriculture, transportation, aviation, space research and many important areas such as water desalination and purification [6]. Studies about investing sulfuric water after treatment with the use of modern technologies is so rare, and the information about the use of them for irrigation is not available enough to rely on, so the current study was selected to enhance that information. In a study of treatment of industrial wastewater for the factories of spinning and fabric and tanneries in Nineveh governorate before flows in Tigris river basin in the city of Mosul, the results showed after the magnetic treatment of samples of water a positive impact on treatment water qualities and recommended to using that treated water for agrarian irrigation [7]. It was also found, that the magnetic technology showed the ability to remove all spores in bacterial count in sewage wastewater which have dangerous diseases on human beings, and the experimental tests show the ability of different magnetic flux densities 500, $1000 \& 1500$ Gauss to reduce all types of bacteria under study with retention time of $10 \mathrm{~min}$. and $20 \mathrm{~min}$. [8]. It was also found that using nanotechnology, palm charcoal as cheap stuff, and simple techniques for treating rich sulfuric spring water in the Hitt area (Ramadi, west Iraq) on the Euphrates River. The results showed high efficiency in the disposal of sulfur ions and the improvement of some Physical and chemical properties of water after treatment. In this study, the efficiency of removing sulphate ion from sulfuric water was 99\% [9].

Recently, many modern methods have appeared for the purpose of treatment, including the use of ozone gas: it is a highly oxidizing chemical that appeared as an alternative to chlorine (that have side effects on human health) where some experts linked it to cancer. And ozone gas has proven its great ability to purify water If it is used in the correct proportions without increasing or decreasing, as the increase in its percentage works to chemical reactions with some compounds, and the water is purified by it by filling special tanks with polluted water and passing it mechanically through filters to mix the water with ozone gas that dissolves the pollutants in the water into its components Initial, increasing oxygen levels to make them drinkable. In addition to that, the method of ultraviolet rays: it is a modern technology that has proven effective in eliminating bacteria and polluting organisms in the water that are resistant to disinfectant chemicals, as the water in the tanks or special stones is exposed to ultraviolet rays without contacting it to eliminate the DNA Of each bacterial organism, or the water is passed through ultraviolet tubes. Also there is Ultrasound method: This technology is called an environmentally friendly technology for water purification, as it does not leave any harmful side effects to the environment, and the water is purified by it by transmitting ultrasound waves to the water at high frequencies that exceed the ability of human hearing that leads to the killing of large proportions of bacterial organisms that pollute the water [15]

How to magnetize water and theories of magnetization: water is a polymagnetic substance, and it bears the paramagnetic properties of $15 \%$ due to the presence of positive and negative ions dissolved in the water. Diamagnetic materials are characterized by complete orbits when exposed to a magnetic field, as they are weakly scattered with water molecules perpendicular to the lines of magnetic flux. Industrial water is treated using devices called (magnetrons) which have different magnetic intensities, one of which is monopole called (magnetizer) used in the medical field a lot, and the dipole (diamagnetic) is used in the industrial field and contains the north (-) and south poles (+) The poles are placed at a certain angle, facing each other, and the water passes so that the water molecules are perpendicular to the magnetic flux lines. There are two physical theories that are the most common in explaining the phenomenon of magnetization; they are Quantum theory and Hydrodynamic theory [16].

\section{Materials and Methods}

This study was made at the Technical Institute / Mosul in the department of water resources techniques. Three areas were selected from Nineveh governorate which contained sulfuric water. The first (A) Mosul dam area, the second (B) Ain Kebriet area in center of Mosul, and the third (C) Hammam Alalil in southern of Nineveh governorate. Twenty litters of sulfuric water from each above area were taken as samples for test and stored at $25^{\circ} \mathrm{C}$, and then laboratory analysis was achieved to determine the characteristics of sulfuric water. Sulfuric water analysis was performed for all three types (A, B, C) by laboratory tests of physical and chemical properties by using the methods of analysis mentioned in $[10,11,12]$. The physical properties for all samples of sulfuric water (color and smell) were studied as well as chemical properties $(\mathrm{pH}$, electrical conductivity (Ec), total dissolved solids (TDS) and $\left(\mathrm{SO}_{4}\right)$. For ( $\mathrm{pH}, \mathrm{Ec}$ and TDS were measured by ( $\mathrm{pH}, \mathrm{Ec}, \mathrm{TDS}$ digital meter) and $\left(\mathrm{SO}_{4}\right)$ estimated by means of the gravimetric method. The following describes the equipment and materials used, that the Magnetism consists of three magnetic rods (1000 Gs, $2000 \mathrm{Gs}$ and $3000 \mathrm{Gs}-\mathrm{Gs}$ is Gauss) respectively. These magnetic rods are connected to a network of metal.tubes that are closed and opened by taps so that each pole can be operated separately. In order to pass water to the magnetic rod, it is placed in a basin then a suitable water pump is placed with plastic pipes in a way that allows the water to pass through a closed circuit during the duration of this process. The experiments were carried out through encoding the samples before starting the processing. After taking the samples of the sulfuric water from the three areas, the samples were marked 
with (A) for the area of the Mosul dam project and (B) for the area of Ein Kebriet, (C) for Hammam - Alalil area. For physical tests (color and smell) and Chemical tests (pH, EC, TDS and $\mathrm{SO}_{4}$ ), which were reached at the laboratory of the Chemical Industries and Oil Refining Division at the Technical Institute / Mosul when the implementation of treatment was achieved by using the magnetic technique, where the magnetization of sulfuric water samples was carried out on two levels of the period of time (15 and 30 minutes) by magnetic field $(1000 \mathrm{Gu})$ where the water characteristics were measured before and after magnetization and figure (1) shows the device of magnetic techniques which was used in treating the sulfuric water in all regions.

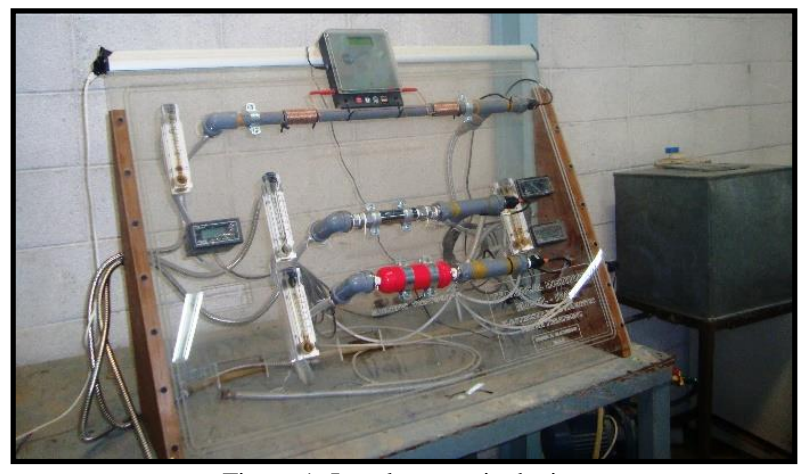

Figure 1: Local magnetic device

\section{Results and discussion}

Generally, water resources suffer from depletion and pollution. So, it requires achieving sustainable development for the water resources by developing contaminated water treatment techniques, which the sulfur water is one of its parts. Therefore, this study was carried out for the sake of treating the sulfuric water in Iraq by the available techniques. Table 1 shows the values of the quality tests made to the sulfuric water samples of the three regions before treatment in order to compare them with the results obtained after the treatment process by magnetic techniques. Table 2 shows the values of the quality tests carried out to the sulfuric water samples of the three regions after treatment by using magnetic technology for (15 minutes and 30 minutes) as they are indicated to in Table 1.

Regarding the chemical properties when comparing in tables (1) and (2), and based on global standards. It was concluded through the tests of chemical properties which have performed after treatment by magnetic techniques are the following where:

1- The pH values: tended towards neutralization after treatment with the magnetic techniques, that the duration of treatment with magnetization (15 and 30 minutes) was sufficient to cause the neutralization process, with the exception of water in the Hammam- alalil bath (C) that may need a longer period or a greater magnetic field strength, where the $\mathrm{PH}$ value changed ; In site (A) from (6) to (7.1), in site (B) from (6.5) to (7.4) and in site (C) from (9) to (8.4)., due to their conversion to hydrogen sulfide gas and their volatilization in the atmosphere, which caused a fault odor in the laboratory . Thus, the flowing of treated water to the river contributes in the enrichment of surface water, and the treatment of sulfuric water by magnetic techniques in order to use it in agricultural irrigation.

2- Electrical conductivity $(\boldsymbol{E C})$ : showed decrease in values to (99\%) through comparing tables (1) and (2); this indicates that the ability of magnetic processing to dissolve the saline sulfurs molecules and release hydrogen ion into water, where the Electric conductivity ( Ec) decreased; in site (A) from (1721 $\mathrm{ppm})$ to $(17 \mathrm{ppm})$, in site (B) from (1414 ppm) to (15 ppm) and in site (C) from (871 ppm) to (9).

3- Total dissolved solids (TDS): Values increased to (6\%-8\%) when using the magnetic techniques, because process of magnetization contributes in the deposition of many substances ,which total dissolved solid (TDS) values are increased in site (A) from $\left(3.5 \times 10^{3} \mathrm{ppm}\right)$ to $\left(3.8 \times 10^{3} \mathrm{ppm}\right)$, in site $(\mathrm{B})$ from $\left(2.8 \times 10^{3} \mathrm{ppm}\right)$ to $\left(3.1 \times 10^{3} \mathrm{ppm}\right)$ and in site $(\mathrm{C})$ from $\left(1.7 \times 10^{3}\right.$ $\mathrm{ppm})$ to $(1.8 \times 103 \mathrm{ppm})$, the matter which led to the efficiency of treatment by increasing the solubility of water contents.

4- Sulfate ion $\left(\mathrm{SO}_{4}\right)$ : the Sulfate values $\left(\mathrm{SO}_{4}\right)$ decreased in the (A) from (1392 ppm) to (144), in the (B) from (945 ppm) to (95 $\mathrm{ppm}$ ) and in site (C) from (247) to (26). Sulfate contributes to the formation of permanent acidity in water, especially in the form of calcium sulphate or magnesium, and is included in saline elements. It is clear from the results that the most specific qualities of sulfuric water do not meet the international standards and is not recommended to be used in normal condition only after being treated with the best method of environmental protection, both on the level of the biosphere to dispose the causes of pollution to add an additional water resource for the river beside some secondary uses, and that is one way to solve the problem of water depletion and pollution. Tables (1) and (2) showed all values decreased except for the values of total dissolved solids which increased as a result of melting and disintegration of particles.

Finally, the study showed that it is necessary to make sulfuric water treatment by using magnetic technology in order to use the treated water in some fields or aspects of life such as agricultural irrigation, where the discharge of treated water to the river contributes in the enrichment of surface water which coincides with the findings of some previous studies which assert, that the magnetic field has a clear impact on the values of $\mathrm{pH}$, TDS and EC with different flow rates when slower flow rates have better effect for water treatment than faster flow rates. On the other hand, increasing the time of passing through of the water through the PWTD raised the efficiency of treatment. Exposing water to a wider area of the magnetic field will increase the changes in water properties. The flow rate of (0.1) lit/sec with three times of passing (3x) increased $\mathrm{pH}, \mathrm{EC}$ in average by $3.7 \%, 9.6 \%$ respectively $[13,14]$. When we compare all results of our study with [7], we find that they are more identical, where all chemical and physical properties of industrial water decreased by using magnetic technology to more than $90 \%$. Also if we compare our study with another modern technology treatment for sulfuric water, and in magnetic technology [8] and nanotechnology as in [9], we notice the consistency of the results demonstrated high efficiency in removing the sulfur ion and improving some of the physical and chemical properties of the water after treatment, reached $99 \%$ compared to the concentrations before treatment. The insufficiently treated of polluted water causes into the water the pollution and change the properties of water, these changes are expressed in particular in the appearance of unpleasant odors, flavors, color change also the changes in the Chemical composition of water such as Acidic number ( $\mathrm{PH})$, Biological Oxygen Demand, Chemical Oxygen Demand, turbidity, Sulphate, Phosphates, Nitrates, Nitrite, Chloride. Due to for technological development, it is possible minimizing the harmful impact of human activities on water resources, the key must be treatment of polluted for water. 
Table 1: Results of quality tests before treatment (EC, TDS and $\mathrm{SO}_{4}$ in ppm)

\begin{tabular}{|c|c|c|c|c|c|c|}
\hline \multirow[t]{3}{*}{ Sample } & \multirow{2}{*}{\multicolumn{2}{|c|}{ Physical tests }} & \multicolumn{4}{|c|}{ Chemical tests } \\
\hline & & & \multirow[t]{2}{*}{ pH } & \multirow[t]{2}{*}{ EC } & \multirow[t]{2}{*}{ TDS } & \multirow[t]{2}{*}{$\mathrm{SO}_{4}$} \\
\hline & Color & Smell & & & & \\
\hline $\mathbf{A}$ & Transparent yellow & Chemical & 6.00 & 1721 & $3.5 \times 10^{3}$ & 1392.00 \\
\hline B & Transparent yellow & Chemical & 6.50 & 1414 & $2.8 \times 10^{3}$ & 945.00 \\
\hline $\mathbf{C}$ & Transparent yellow & Chemical & 9.00 & 871 & $1.7 \times 10^{3}$ & 247.00 \\
\hline
\end{tabular}

Table 2: Results of quality tests after treatment (Magnetic technology) (EC, TDS and $\mathrm{SO}_{4}$ in $\mathrm{ppm}$ )

\begin{tabular}{|c|c|c|c|c|c|c|}
\hline \multirow[t]{3}{*}{ Sample } & \multirow{2}{*}{\multicolumn{2}{|c|}{ Physical tests }} & \multicolumn{4}{|c|}{ Chemical tests } \\
\hline & & & \multirow{2}{*}{$\begin{array}{c}\mathrm{pH} \\
-\end{array}$} & \multirow[t]{2}{*}{$\mathbf{E C}$} & \multirow[t]{2}{*}{ TDS } & \multirow{2}{*}{$\mathrm{SO}_{4}$} \\
\hline & Color & Smell & & & & \\
\hline AM-15 & Transparent & Very acceptable & 7.20 & 17.00 & $3.7 \times 10^{3}$ & 144.00 \\
\hline AM-30 & Transparent & Very acceptable & 7.10 & 16.90 & $3.8 \times 10^{3}$ & 141.00 \\
\hline ВM-15 & Transparent & Very acceptable & 7.50 & 15.00 & $3.0 \times 10^{3}$ & 101.00 \\
\hline ВM-30 & Transparent & Very acceptable & 7.40 & 15.80 & $3.1 \times 10^{3}$ & 95.00 \\
\hline CM-15 & Transparent & Very acceptable & 8.70 & 9.00 & $1.8 \times 10^{3}$ & 33.00 \\
\hline CM-30 & Transparent & Very acceptable & 8.40 & 9.08 & $1.8 \times 10^{3}$ & 26.00 \\
\hline
\end{tabular}

For achievement of sustainable water development, the main object of sewage treatment process is to remove the various constituents of the polluting materials such as solids, organic carbon, nutrients, inorganic salts, metals, pathogens etc. The study [17], offered some apparatus that provides the process of polluted water treatment techniques such as; Suspension centrifuge, Horizontal centrifuge with pulsating piston, Centrifuge with inertial discharge of sediment, Drum vacuum filter, Disc Vacuum Filter, Carousel and suction filter, Belt filter and Centrifugal filter. These apparatus decrease all polluted water properties as in our study, but our technology is simple and more sufficient more economic.

\section{Ethical issue}

Authors are aware of, and comply with, best practice in publication ethics specifically with regard to authorship (avoidance of guest authorship), dual submission, manipulation of figures, competing interests and compliance with policies on research ethics. Authors adhere to publication requirements that submitted work is original and has not been published elsewhere in any language.

\section{Competing interests}

The authors declare that there is no conflict of interest that would prejudice the impartiality of this scientific work.

\section{Authors' contribution}

All authors of this study have a complete contribution for data collection, data analyses and manuscript writing.

\section{References}

1. Zahra A. Eevaluation of the efficiency of some water supply stations in Najaf Governorate using the weighted arithmetic index method (WQI). Muthanna Journal of Engineering and Technology. 2018;6(2):185-199. https://doi.org/10.18081/mjet/2018-6/185-199

2. Salih MA, Sura A. Assessment of sulfurous springs in the west of Iraq for balneotherapy, drinking, irrigation and aquaculture purposes. Environ geochem health. 2014 Jan;36(3):359-370. https://doi.org/10.1007/s10653-013-9555-6

3. Mus'ab A, Laith A. Sulfied removal from sulfide spring. Tikrit Journal of Engineering Sciences. 2007;14(2):80-96.

4. Jose MC, Francisco M. Sulphurous Mineral Waters: New Applications for Health. Evid based complement AlterNet Med. 2017. https://doi.org/10.1155/2017/8034084
5. Almosuli M. Magnetized water. Dar Alyazouri scientific publishing and distribution, Amman, Jordan. 2013;1(1).

6. Alfeeli, B , Ma' moun A, Ali B, Haider A, Mohamed A, Zouhair M. A review of nanotechnology development in the Arab World. Nanotechnol Rev. 2013;2(3):359-377. https://doi.org/10.1515/ntrev-2012-0070

7. Ayham T. The use of magnetic technology in the treatment of industrial waste water from spinning \& weaving and tanning factories in Nineveh to benefit from them in agriculture and irrigation. Agricultural Journal, University of Tikrit, Iraq. 2011;10(2):138-142.

8. Sufyan M, Khalid A, Ahmed A, Ahmed J, Ahmed Al. Magnetized water and its effects on the reduction of the microbial content of sewage wastewater. Iraqi journal of science and technology. 2013;4(2):64-69.

9. Zedan T, Emad A, Mohammed S, Mohammed W. Development of an economical way to remove sulfur in sulfuric water using activated charcoal from palm kernel. Pure sciences Journal, University of Alanbar, Iraq. 2012;6(3):34-48.

10. Jabro A, Amul M. Health chemistry. Foundation of Technical Institutes, Ministry of higher education and scientific. 1993.

11. Abawi S, Mohammed S. Practical Engineering of the Environment, Water Testing. Dar al-Hikma for Printing and Publishing, Mosul, Iraq. 1990.

12. APHA, WPCF, AWWA. Standard Methods for the Examination of Water and Wastewater. 20 ${ }^{\text {th }}$ ed., Washington, D.C. 1998.

13. Kadhim N, Ahmed R. Experimental Study of Magnetization Effect on Ground Water Properties. Jordan Journal of Civil Engineering. 2018;12(2):254-262.

14. Tariq $\mathrm{N}$. The effect of magnetic field on the solubility of $\mathrm{NaCl}$ and $\mathrm{CaCl}_{2} \cdot 2\left(\mathrm{H}_{2} \mathrm{O}\right)$ at different temperature and $\mathrm{pH}$ values. Basrah Journal of Agricultural Sciences. 2012;25(1):19-26. https://doi.org/10.33762/bagrs.2012.54751

15. McCooke, N, West J. The Coagulation of Kaolinite Suspension with aluminum Sulfate. Water research. 1978;12(10):793-798. https://doi.org/10.1016/0043-1354(78)90029-5

16. Sulav A. Aspects of benefiting from magnetized water technology in agriculture and public health in Iraq. Journal of the College of Basic Education. 2016;22(94):481-500.

17. Alias M, Ayham T, Mohammed A. Negative Effect of Sewage Water on Environment and Techniques of Treatment. International Journal of Management and Applied Science. 2019;5(1):46-50. IRAJ DOI Number - IJMAS-IRAJ-DOI-14979 